\title{
Inventário arbóreo e percepção da população sobre a arborização urbana na Cidade de Balsas-MA
}

\author{
Arbory inventory and the population's perception of urban afforestation in the City of Balsas-MA \\ Inventario arbóreo y percepción de la población sobre la forestación urbana em la Ciudad de \\ Balsas-MA
}

\section{Resumo}

A arborização urbana é um elemento essencial para elevar a qualidade de vida da população. Tendo em vista que a arborização urbana é insuficiente na maioria das cidades do país, esse problema é mais visível na cidade de BalsasMA, onde umas boas parcelas das ruas e avenidas não estão arborizadas corretamente e suficiente. O trabalho tem como objetivo realizar um inventário quali-quantitativo das espécies na arborização de Balsas-MA e compreender a percepção da população sobre a arborização de Balsas através de da aplicação de um questionário eletrônico. Para a obtenção dos dados, foi realizada a delimitação da área de estudo como sendo o centro da cidade de Balsas, e então foi feita uma caracterização das espécies encontradas por meio de idas a campo para obtenção dos dados. Com base nos dados obtidos, observou-se que existem poucos indivíduos arbóreos e que espécies exóticas dominam a área estudada, sendo o Nim (Azadirachta indica) correspondente a 50\% das árvores. Com relação a percepção da população, os dados obtidos mostram que grande parte da população desconhecem os malefícios gerados por uma arborização inadequada, porém reconhecem os benefícios e embora tenham atribuindo a responsabilidade da arborização da cidade à prefeitura, a maioria dos entrevistados estariam dispostos a contribuir na manutenção da arborização da cidade. Espera-se que o estudo possa subsidiar a implementação do Plano Municipal de Arborização Urbana na cidade de Balsas, contemplando ações de curto, médio e longo prazo.

Palavras-chave: Arborização; Inventário; Percepção ambiental.

\begin{abstract}
Urban afforestation is an essential element in raising the population's quality of life. Bearing in mind that urban afforestation is insufficient in most cities in the country, this problem is more visible in the city of Balsas-MA, where a good portion of the streets and avenues are not properly and sufficiently forested. The work aims to carry out a qualitative and quantitative inventory of the species in the afforestation of Balsas-MA and to understand the population's perception of the afforestation of Balsas through the application of an electronic questionnaire. To obtain the data, the study area was delimited as being the center of the city of Balsas, and then a characterization of the species found through field trips was made to obtain the data. Based on the data obtained, it was observed that there are few arboreal individuals and that exotic species dominate the studied area, with Nim (Azadirachta indica) corresponding to $50 \%$ of the trees. Regarding the perception of the population, the data obtained show that a large part of the population is unaware of the harm caused by inadequate afforestation, but they recognize the benefits and although they have attributed the responsibility for the afforestation of the city to the city hall, most of the interviewees would be willing to contribute. maintaining the city's afforestation. It is hoped that the study can support
\end{abstract}


the implementation of the Municipal Plan for Urban Arborization in the city of Balsas, covering short, medium and long term actions.

Keywords: Afforestation; Inventory; Environmental perception.

\begin{abstract}
Resumen
La forestación urbana es un elemento fundamental para mejorar la calidad de vida de la población. Teniendo en cuenta que la forestación urbana es insuficiente en la mayoría de las ciudades del país, este problema es más visible en la ciudad de Balsas-MA, donde una buena parte de las calles y avenidas no están adecuadamente y suficientemente forestadas. El trabajo tiene como objetivo realizar un inventario cualitativo y cuantitativo de especies en la forestación de Balsas-MA y comprender la percepción de la población sobre la forestación de Balsas mediante la aplicación de un cuestionario electrónico. Para la obtención de los datos se delimitó el área de estudio como el centro de la ciudad de Balsas, y luego se realizó una caracterización de las especies encontradas a través de viajes de campo para obtener los datos. Con base en los datos obtenidos, se observó que hay pocos individuos arbóreos y que las especies exóticas dominan el área de estudio, correspondiendo Nim (Azadirachta indica) al 50\% de los árboles. En cuanto a la percepción de la población, los datos obtenidos muestran que gran parte de la población desconoce el daño que ocasiona la forestación inadecuada, pero reconocen los beneficios y aunque han atribuido la responsabilidad de la forestación de la ciudad a la alcaldía., la mayoría de los entrevistados estarían dispuestos a contribuir al mantenimiento de la forestación de la ciudad. Se espera que el estudio pueda apoyar la implementación del Plan Municipal de Arborización Urbana en la ciudad de Balsas, cubriendo acciones de corto, mediano y largo plazo.
\end{abstract}

Palabras clave: Forestación; Inventario; Percepción ambiental.

\title{
1. Introdução
}

A falta de planejamento e gestão no processo de expansão de áreas urbanas são os principais causadores de impactos ambientais relacionados a supressão da vegetação e redução de biodiversidade (Amato-Lourenço, Moreira, Arantes, Silva Filho, \& Mauad, 2016), o que tem comprometido na conservação e integridade das áreas verdes nos centros urbanos. A arborização urbana engloba conjunto de áreas públicas ou privadas com vegetação predominantemente arbórea ou em estado natural que uma cidade apresenta, incluindo as árvores das ruas, avenidas, parques públicos e demais áreas verdes (Pagliari \& Dorigon ,2013).

A presença de vegetação nos centros urbanos possibilita inúmeros benefícios para o bem-estar da população, assegurando na melhoria do conforto físico, psicológico e emocional, amenizando os níveis de ansiedade e estresse (Gonçalves \& Meneguetti, 2015; Schvarstzhaupt \& Reis, 2017). Além disso, a arborização proporciona a redução da temperatura e de ilhas de calor nos centros urbanos absorvendo o gás carbônico, emitido pelos veículos automotores, uns dos gases responsáveis pela intensificação do efeito estufa; diminuição da poluição sonora e atmosférica; diminuição do escoamento superficial e possivelmente de enchentes, além do enaltecimento ambiental e artístico da biodiversidade no local (Cemig, 2011; Lira Filho, 2001; Pagliari \& Dorigon, 2013).

De acordo com Bobrowski e Biondi (2012), para assegurar todas as vantagens da arborização urbana sem malefícios para os habitantes de uma cidade e sua estrutura, esta tem que ser desenvolvida por meio da elaboração de inventário arbóreo que contenha todas as informações sobre as espécies arbóreas utilizadas na cidade, bem como seu estado em relação aos equipamentos urbanos e assim facilitando a manutenção desses indivíduos arbóreos e atenuando seus benefícios. Muitos dos problemas ambientais e estruturais encontrados nos centros urbanos referentes a arborização estão relacionados com o plantio de espécies improprias, reduzindo a biodiversidade e gerando danos as estruturas de calçadas e fiações elétricas (Silva \& Lira, 2014).

Umas das ferramentas que podem auxiliar em um diagnóstico no manejo da arborização urbana é através da percepção ambiental da população na cidade, sendo importante nas soluções de problemas estruturais e na prevenção de impactos ambientais relacionados a falta de planejamento da vegetação urbana (Rodrigues et al., 2010; Sufia et al., 2019). A percepção ambiental, sendo um objeto de estudo, possibilita o acúmulo de conhecimentos e experiências que contribuem na 
compreensão da relação meio ambiente e ser humano, sendo inteiramente conectada as percepções do indivíduo sobre o espaço que ele habita (Almeida et al., 2017).

Diante disso, tendo em vista que os benefícios da arborização urbana estão totalmente interligados ao planejamento adequado das instalações arbóreas na zona urbana, o presente trabalho tem como objetivo a realização um inventário da arborização no Centro de Balsas, no Maranhão, onde os indivíduos foram caracterizados e identificados, além de sugerir informações para a gestão da cidade através da aplicação de questionário eletrônico para entender a percepção ambiental da população em relação a arborização urbana da cidade.

\section{Metodologia}

\subsection{Caracterização da área de estudo}

O presente estudo foi-se realizado no município de Balsas (FIGURA 1) (07 $31^{\prime} 58^{\prime \prime} \mathrm{S} ; 46^{\circ} 02^{\prime} 09^{\prime \prime} \mathrm{O}$ ) localizado na mesorregião sul Maranhense do Estado do Maranhão e possui população estimada de 93.511 habitantes - MA IBGE/2020 de área de 13 141,637 km². A cidade de Balsas possui apenas 32,9\% de domicílios urbanos em vias públicas de arborização e apenas $0,6 \%$ das vias estão em condições adequadas em relação a arborização com presença de bueiros, meio-fio e calçadas (IBGE, 2018).

Figura 1: Mapa de localização da área de estudo.

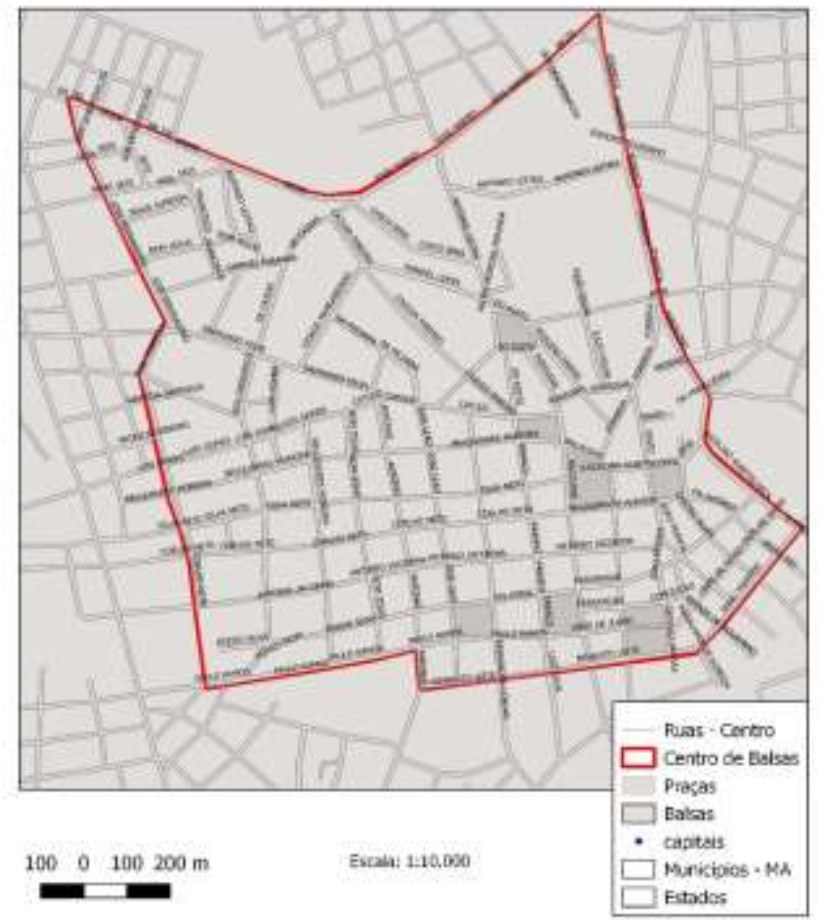

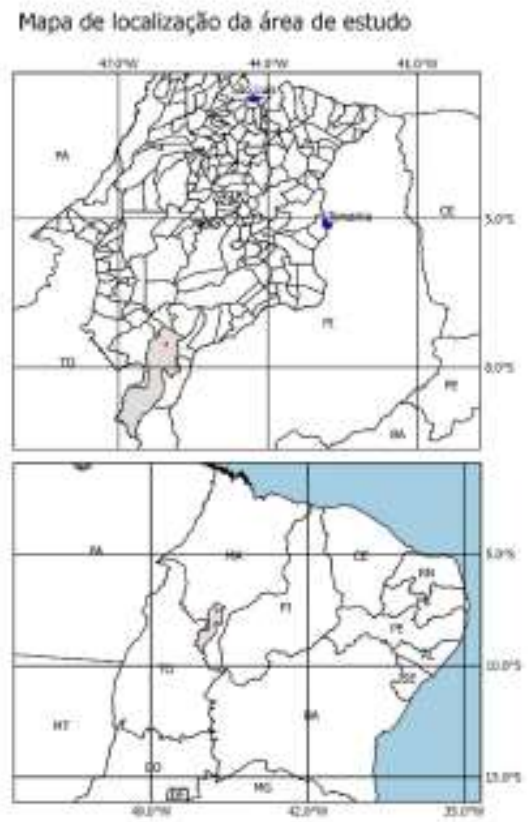

Sryes 2000 UTाM 225

Fonte: Autores.

De acordo com a Figura 1, a delimitação da área central foi baseada no zoneamento realizado pela Prefeitura Municipal, com base no Plano Diretor do município e compreende o polígono delimitado pelas seguintes ruas e avenidas: Avenida Coronel Fonseca; Av. Juscelino Kubitscheck; Rua Luís Gonzaga; Rua Benedito Leite; Rua Santo Antônio; Rua Paulo Ramos; Rua Coelho Neto; Rua José Ferreira; Avenida José Bernardino e o trecho urbano da BR 230 entre as avenidas José Bernardino e Coronel Fonseca. 


\subsection{Metodologia de pesquisa}

O trabalho consiste de pesquisa descritiva quali-quantitativa das espécies arbóreas existentes no perímetro urbano do centro cidade através de um estudo de campo, conforme descrito em Ventura (2002, p. 79), por meio da delimitação da região central da cidade de Balsas-MA e observações diretas do grupo estudado e da população entrevistada através da elaboração e aplicação de um questionário por meio da metodologia de Hartmut Gunther (2003).

O levantamento foi realizado somente em locais como canteiros ou praças e as espécies que foram identificadas e quantificadas. Durante o levantamento quali-quantitativo de campo, todas as ruas foram percorridas para contagem e identificação das espécies arbóreas. Somente foram levantadas informações da arborização que se encontra fora do alinhamento predial.

\subsection{Procedimentos metodológicos}

Após a delimitação da área de estudo, foram realizadas as campanhas de campo que ocorreram no período de setembro a novembro de 2017, levando em consideração apenas as que as árvores que estavam plantadas em perímetro público, mesmo se copa estivesse na área pública. Todas as árvores foram identificadas e quantificadas. Para auxiliar na identificação das espécies, em primeira mão, houve o contato com moradores para identificar os nomes populares e então foi realizada a confirmação por meio de pesquisas na internet e comparação com as espécies descritas na coleção Árvores Brasileiras, escrita por Harry Lorenzi, edições de 1992, 1998 e 2009. As imagens das árvores foram registradas através de câmera fotográfica.

Na última parte de identificação, as árvores analisadas foram identificadas de acordo com a espécie. Devido à grande presença de plantas que ainda estavam pequenas e ausência de fatores característicos, como no caso do ipê (floração por exemplo), existe uma grande quantidade de espécies como o ipê rosa, ipê amarelo, ipê roxo e etc. Nestes casos, foram identificados somente com $s p$ após o nome científico.

Com a identificação das espécies foi possível determinar quais são nativas ou exóticas. Esta avaliação possibilitou analisar os impactos positivos e negativos que estas poderiam causar ao meio, de acordo com o que foi encontrado na literatura.

Para a realização do questionário objetivando conhecer a percepção da população de Balsas sobre as vantagens e desvantagens da arborização, a coleta de dados foi realizada através da internet, por meio da criação do questionário no Google formulários, que foi compartilhado via aplicativo de mensagens e redes sociais. O critério de escolha dos participantes foi essencialmente pessoas que residem na cidade de Balsas. O Quadro 1 mostra as perguntas utilizadas no questionário. 
Quadro 1. Listas de perguntas realizados aos entrevistados.

\begin{tabular}{|c|c|c|}
\hline Pergunta & Possíveis respostas & Observações \\
\hline Gênero & $\begin{array}{l}\text { a) Masculino } \\
\text { b) Feminino }\end{array}$ & Resposta única \\
\hline Faixa etária & $\begin{array}{l}\text { a) até } 18 \text { anos } \\
\text { b) De } 19 \text { a } 30 \text { anos } \\
\text { c) De } 31 \text { a } 45 \text { anos } \\
\text { d) } 46 \text { anos ou mais }\end{array}$ & Resposta única \\
\hline Tempo de residência na cidade & $\begin{array}{l}\text { a) Menos que } 1 \text { ano } \\
\text { b) Entre } 1 \text { e } 3 \text { anos } \\
\text { c) Entre } 3 \text { e } 5 \text { anos } \\
\text { d) Mais que } 5 \text { anos }\end{array}$ & Resposta única \\
\hline Número de moradores por residência & $\begin{array}{l}\text { a) Apenas } 1 \\
\text { b) Entre } 2 \text { e } 3 \\
\text { c) } 4 \text { moradores } \\
\text { d) mais que } 4\end{array}$ & Resposta única \\
\hline Escolaridade & $\begin{array}{l}\text { a) Ensino fundamental incompleto } \\
\text { b) Ensino fundamental completo } \\
\text { b) Ensino médio completo } \\
\text { c) Ensino Superior completo } \\
\text { d) Pós-graduação: especialização, mestrado ou doutorado }\end{array}$ & Resposta única \\
\hline $\begin{array}{c}\text { Aponte que vantagens abaixo você } \\
\text { atribui a presença de árvores nas ruas do } \\
\text { centro de Balsas }\end{array}$ & $\begin{array}{l}\text { a) Produção de flores e frutos } \\
\text { b) Embelezamento das ruas } \\
\text { c) Melhor qualidade do ar } \\
\text { d) Redução da poluição sonora } \\
\text { e) Redução de calor } \\
\text { f) Sombreamento }\end{array}$ & Múltipla escolha \\
\hline $\begin{array}{c}\text { Aponte que desvantagens abaixo você } \\
\text { atribui a presença de árvores nas ruas do } \\
\text { centro de Balsas }\end{array}$ & $\begin{array}{l}\text { a) Não observou nenhum ponto negativo } \\
\text { b) Problema calçada devido às raízes } \\
\text { c) Problemas com rede elétrica e telefônica } \\
\text { d) Redução da iluminação pública } \\
\text { e) Sujeira de ruas e calçadas }\end{array}$ & Múltipla escolha \\
\hline $\begin{array}{c}\text { De quem você acha que é a } \\
\text { responsabilidade da arborização urbana } \\
\text { na cidade de balsas? }\end{array}$ & $\begin{array}{l}\text { a) Dos próprios moradores } \\
\text { b) Prefeitura }\end{array}$ & Resposta única \\
\hline $\begin{array}{l}\text { O que você acha que deve ser feito para } \\
\text { melhorar a arborização urbana na } \\
\text { cidade? }\end{array}$ & $\begin{array}{l}\text { a) Criar um sistema de multas } \\
\text { b) Conscientização da população } \\
\text { c) Maior manutenção e podas de árvores } \\
\text { d) Plantas mais árvores }\end{array}$ & Múltipla escolha \\
\hline $\begin{array}{l}\text { Com relação a arborização urbana você } \\
\text { estaria disposto (a) a contribuir } \\
\text { financeiramente para o plantio e } \\
\text { manutenção da arborização de sua } \\
\text { cidade? }\end{array}$ & $\begin{array}{l}\text { a) Sim, contribuiria com } R \$ 5,00 \text { (dez reais) por ano } \\
\text { b) Sim, contribuiria com } R \$ 10,00 \text { (dez reais) por ano } \\
\text { c) Sim, contribuiria com } R \$ 15,00 \text { (dez reais) por ano } \\
\text { d) Não contribuiria. }\end{array}$ & Resposta única \\
\hline
\end{tabular}

Fonte: Autores.

As respostas do questionário aplicado poderiam ser únicas ou de múltipla escolha e ficou disponível para acesso durante um mês para alcançar o máximo de respostas possíveis dos entrevistados sobre suas opiniões em relação a arborização da cidade. Logo após esse prazo, os dados foram tabulados em programas como Microsoft Excel e Word e por fim analisados para compreender o ponto de vista da população.

\section{Resultados e Discussão}

Por meio do levantamento realizado no centro da cidade de Balsas, foi possível identificar os principais problemas, plantio de mudas com espécies inapropriadas para os locais e algumas árvores mortas. 


\subsection{Escolha e plantio de espécies}

Através da pesquisa de campo foi possível a elaborar o mapa de distribuição das espécies nativas, exóticas ou mortas (Figura 2) para demonstrar quantitativamente como as espécies arbóreas estão distribuídas na área de estudo.

Figura 2. Distribuição e distinção das espécies arbóreas na área de estudo.

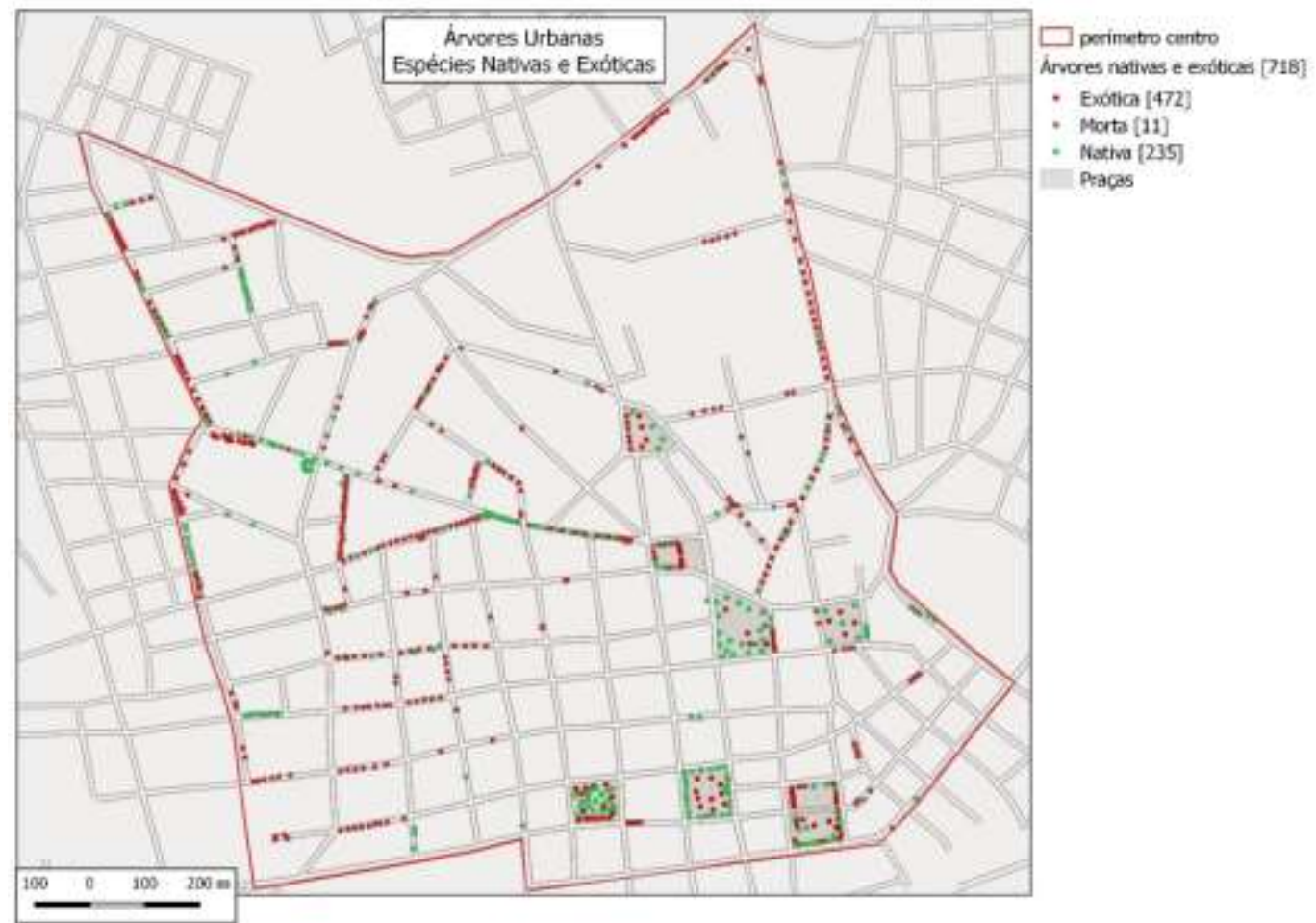

Fonte: Autores.

De acordo com a Figura 2, foram quantificados 718 indivíduos arbóreos no centro da cidade de Balsas, pertencentes a 30 espécies diferentes. Em relação ao tipo de espécies, 472 árvores (cerca de 65,7\%) são exóticas e 235 (cerca de 34,3\%) são nativas. Valores semelhantes ao encontrados no inventário arbóreo da cidade de Tianguá- CE, constatando a presença de 69,45\% de espécies exóticas e 30,55\% de nativas (Araújo et al.,2017). A introdução de espécies exóticas detém algumas características positivas por influenciar no paisagismo, entretanto, a competição com a flora nativa pode incrementar na redução da biodiversidade local por conta da toxicidade e disputa de território (Santos et al., 2014: Periotto et al., 2016; Sousa et al., 2019). De acordo com Sjöman et al. (2016), as espécies exóticas não necessitam serem removidas das vias urbanas, todavia, devem ser aplicadas no intuito de agregar na flora local.

O Quadro 2 representa as espécies encontradas na área de estudo com identificação por nome comum e científico de acordo com as regras de taxonomia botânica. Dentre as espécies nativas, verificou-se que a Licania tomentosa (Oiti) foi a espécie mais encontrada, com cerca de 7,54\%, seguida pela família Handroanthus sp. (Ipê) 5,73\% e a espécie Caesalpinia pluviosa (sibipiruna) $4,18 \%$. 
Quadro 2: Espécies arbóreas encontradas na área central da cidade de Balsas-MA.

\begin{tabular}{|c|c|c|c|}
\hline Nome comum & Espécie & Ocorrência & No. De árvores \\
\hline Acerola & Malphigia ermaginata & Exótica & $0,14 \%$ \\
\hline Ata/Pinha & Annona squamosa & Exótica & $0,28 \%$ \\
\hline Cajueiro & $\begin{array}{c}\text { Anacardium } \\
\text { occidentale }\end{array}$ & Nativa & $1,95 \%$ \\
\hline Canafístula & Cassia fistula & Exótica & $0,28 \%$ \\
\hline Ciprestre & $\begin{array}{c}\text { Cupressus } \\
\text { sempervirens }\end{array}$ & Exótica & $0,14 \%$ \\
\hline Coqueiro & Cocos nucifera & Nativa & $0,42 \%$ \\
\hline Ficus & Ficus bejamina & Exótica & $1,53 \%$ \\
\hline Flamboyant & $\begin{array}{c}\text { Delonix regia (Hook) } \\
\text { raf. }\end{array}$ & Exótica & $1,95 \%$ \\
\hline Goiaba & Psidium guajava & Exótica & $0,14 \%$ \\
\hline Ipê & Handroanthus sp. & Nativa & $5,71 \%$ \\
\hline Ipêzinho de Jardim & Tecoma stans & Exótica & $1,95 \%$ \\
\hline Jambo & Syzygium malaccense & Exótica & $2,92 \%$ \\
\hline Jamelão & Syzygyum cumini & Exótica & $0,42 \%$ \\
\hline Jussara & Euterpe edulis & Nativa & $0,68 \%$ \\
\hline Limoeiro & Citrus limonum & Exótica & $0,14 \%$ \\
\hline Mamorana & Pachira aquatica & Nativa & $2,91 \%$ \\
\hline Manga & Mangifera indica & Exótica & $5,15 \%$ \\
\hline \multicolumn{2}{|l|}{ Mortas } & & $1,53 \%$ \\
\hline Nim & Azadirachta indica & Exótica & $50,14 \%$ \\
\hline Noni & Morinda citrofolia $L$. & Exótica & $0,14 \%$ \\
\hline Oiti & Licania tomentosa & Nativa & $7,54 \%$ \\
\hline Palmeira & Palmae sp. & Ext/Nat & $3,06 \%$ \\
\hline Palmeira Imperial & Roystonea oleracea & Exótica & $1,39 \%$ \\
\hline Pata de vaca & Bauhinia variegata & Nativa & $0,84 \%$ \\
\hline Pequi & Caryocar brasiliense & Nativa & $0,14 \%$ \\
\hline Pitanga & Eugenia uniflora & Nativa & $0,14 \%$ \\
\hline Sete Copas & Terminalia catappa & Exótica & $2,51 \%$ \\
\hline Sombra de Vaca & Clitoria fairchildiana & Nativa & $0,14 \%$ \\
\hline Sibipiruna & Caesalpinia pluviosa & Nativa & $4,18 \%$ \\
\hline Tipuana & Tipuana tipu & Nativa & $1,67 \%$ \\
\hline
\end{tabular}

Fonte: Autores.

Com relação a Tabela 1, dentre as espécies exóticas, a Azadirachta indica (Nim) correspondeu 50,14\% de todos os indivíduos arbóreos encontrados na área de estudo, seguida da Mangifera indica (Mangueira) 5,15\%, Syzygium malaccense (Jambo vermelho) 2,92\% Terminalia catappa (Sete Copas) 2,51\%. A Azadirachta indica está presente em praticamente em quase todas as ruas da região central delimitado para o estudo que contem árvores. Com objetivo de minimizar a infestação de pragas e possibilitar um espaço mais diversificado para a flora local é fundamental que a composição arbórea de uma espécie não ultrapasse 15\% dos indivíduos (Brianezi et al., 2013; Kern et al., 2013), o que comprova que o Nim não está dentro do limite estabelecidos pelos autores citados.

A presença alarmante da Azadirachta indica na arborização da cidade de balsas é uma realidade de quase todo o nordeste brasileiro. Diversos inventários arbóreos realizados na região indicam uma infestação da espécie no componente arbóreos das cidades (Lucena et al., 2015; Rufino et al., 2019). É extremamente preocupante a presença em larga escala do Nim indiano, pois a espécie promove alterações ecológicas nos ecossistemas, reduzindo a presença da flora nativa pela sua toxicidade no processo de germinação dessas espécies (Leão et al.,2011; Frabicante, 2014). Além de disso, o nim também é uma grande ameaça a fauna local por provocar a morte de agentes polinizadores, principalmente as abelhas, devido suas propriedades inseticidas (Frabricante et al., 2017). 
Foram encontradas mais algumas espécies impróprias para a arborização urbana, como por exemplo, algumas espécies frutíferas como a Mangifera indica (Mangueira) com 5,15\%. Resultado similiar encontrado por Batista et al. (2012) na caracterização das espécies arbóreas cidade de Regimo-PB, das 10 espécies encontradas (6,5\%), 3\% correspondeu a Mangifera indica. A espécie Syzygium malaccense correspondeu a 2,92\% das arvores encontradas, valores próximos encontrados no inventário arbóreo realizado na cidade de Beberibe $(4,03 \%)$ realizado por (Moro \& Westerkamp, 2011). Apesar da pequena porcentagem, a mesma apresenta potencial invasor alto (Sampaio \& Schmidt, 2013).

As introduções de espécies frutíferas possibilitam a disseminação das sementes pelas aves e alimentação da fauna silvestre e de humanos, porém os frutos devem ser pequenos (Rabelo et al., 2019). Em estudo realizado por Valdiclei et al. (2017) sobre o inventário da arborização urbana no bairro Cidade Alta, no município de Cuiabá, Mato Grosso, acentuam a precaução sobre a utilização da Mangifera indica, na composição arbórea da cidade, por a mesma possuir raízes volumosas que ocasionam danos as estruturas de calçadas, meio fio e contato com fiações elétricas, além de produzir frutos grandes, que quando maduros, oferecem risco a população e após a queda, geram sujeiras e atraem insetos para o local. Uns dos principais motivos que podem reduzir a biodiversidade da flora nativa são a introdução de espécies sem um embasamento cientifico sobre os impactos ambientais que as mesmas podem ocasionar, além da falta de comprometimento com as normas e regras estabelecidas pela legislação sobre arborização urbana (Hoppen et al., 2014).

\subsection{Percepção da população sobre arborização urbana}

Para conhecer a percepção da população com relação a arborização urbana, foi essencial a aplicação do questionário eletrônico com diversas perguntas a respeito da arborização. A Figura 3 representa o perfil dos indivíduos entrevistados no questionário sobre a percepção da arborização da cidade de Balsas.

Figura 3: Perfil dos entrevistados no questionário eletrônico.

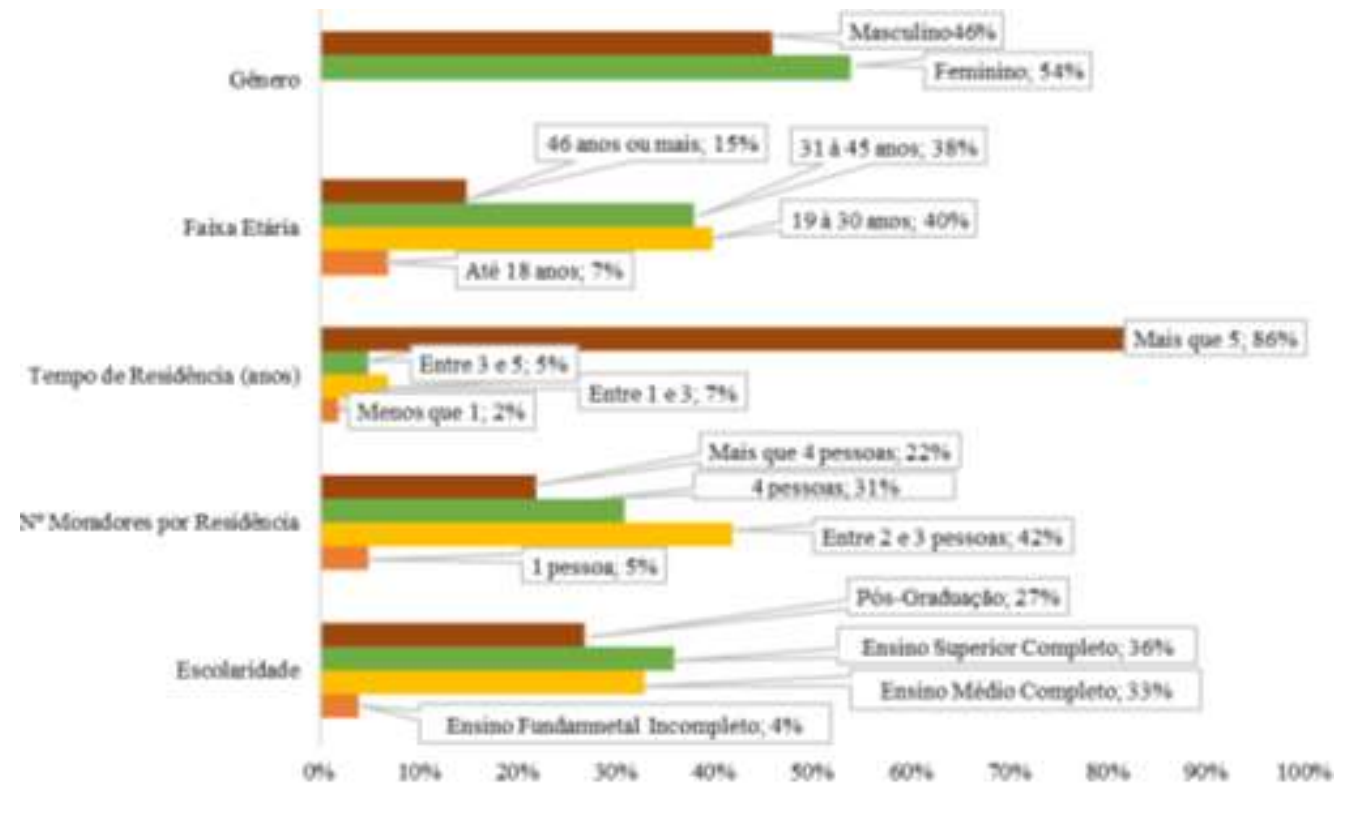

Fonte: Autores (2018).

De acordo com a Figura 3, dos totais de entrevistados cerca de 54\% eram do gênero feminino e $46 \%$ do masculino. Em relação a faixa etária, $40 \%$ estão na faixa de 19 à 30 anos; 38\% entre 31 à 45 anos e 15\% possuem mais de 46 anos de idade. Quanto ao tempo de residência, $86 \%$ dos entrevistados residem na cidade a mais de 5 anos, $7 \%$ entre 1 a 3 anos e $5 \%$ 
entre 3 e 5 anos. Cerca de $42 \%$ dos entrevistados possuem 2 ou 3 pessoas morando em casa, $31 \%$ vivem com 4 pessoas e $22 \%$ residem com mais de 4 pessoas. Quanto ao grau de escolaridade, 36\% dos entrevistados possuem ensino superior completo; $33 \%$ apresentam ensino médio completo e $27 \%$ possuem pós-graduação. Nesse sentindo, o grau de escolaridade pode influenciar positivamente a percepção ambiental, por meio de uma análise cientifica e consciente da população (Meyer, 2015).

\subsection{Percepção dos entrevistados quanto as vantagens e desvantagens da arborização}

De acordo com a Figura 4, é possível perceber que a maioria dos entrevistados compreendem os benefícios da arborização urbana, enquanto uma parte não observou nenhum ponto negativo.

Figura 4: Percepção dos entrevistados quanto as vantagens e desvantagens da arborização.

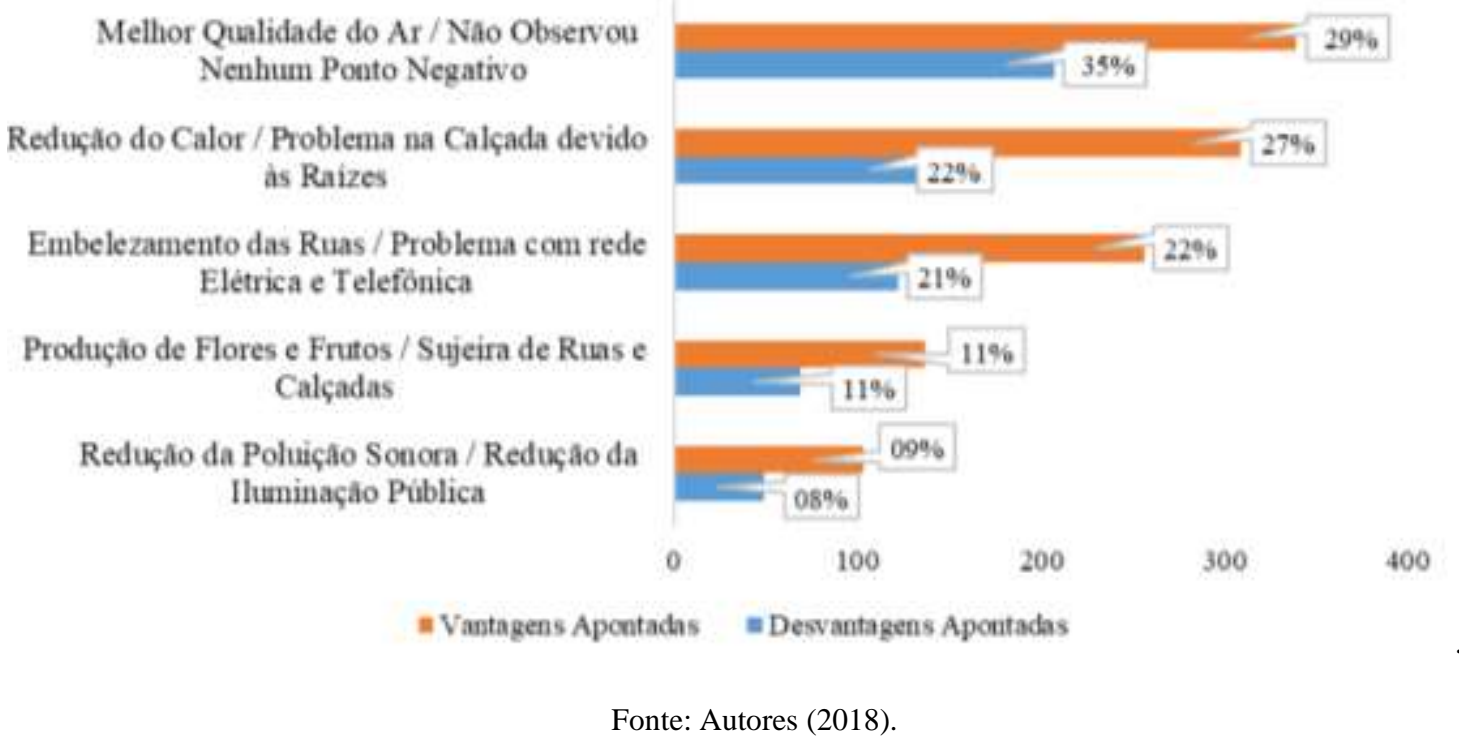

De acordo com a Figura 4, cerca de $29 \%$ dos entrevistados relataram que a arborização proporciona uma melhoria da qualidade do ar; $27 \%$ citaram a diminuição do calor; $22 \%$ afirmaram que arborização promove embelezamento das vias públicas; $11 \%$ relatam a produção de flores e frutos e $9 \%$ citaram a redução da poluição sonora, sendo importante ressaltar que foi a vantagem menos respondidas pelos entrevistados. Valor próximo ao encontrado no estudo de De Oliveira et al. (2020), cerca de $6 \%$ citaram a redução da poluição sonora no questionário aplicado.

Em relação as vantagens citadas acima, fica perceptível a percepção dos moradores de balsas, que a presenças de arborização nas vias públicas podem trazer conforto térmico através da redução de calor; melhoria da qualidade do ar e sensação de bem-estar. De acordo com Lopo (2014), a redução da temperatura acontece devido a evapotranspiração e pela absorção direta da radiação solar pela copa das árvores, o que faz que aumente a incidência do sombreamento, o que faz com que a sensação de conforto térmico permaneça.

Quanto às desvantagens; 35\% relataram que a arborização não apresenta desvantagens; $22 \%$ citam os problemas estruturais as calçadas e pavimentos por conta do crescimento radicular das árvores; $21 \%$ os problemas com o contato com redes de fiações elétricas e telefonias; $11 \%$ relataram que a arborização ocasiona o aparecimento de sujeira de ruas e calçadas por conta das folhas, flores e frutos e $8 \%$ citam a redução da iluminação pública. É importante apontar que a maioria dos entrevistados não reconhecem os efeitos negativos da falta de arborização uma vez os benefícios da presença de arborização são maiores que os possíveis malefícios que podem ser observados. 
No município de Barra Bonita-SP, no estudo realizado por Guerreiro et al. (2020), cerca 40,9\% dos entrevistados não apontaram nenhuma desvantagem sobre arborização, porém $29,9 \%$ citaram a sujeira de ruas e $16,5 \%$ os problemas com equipamentos urbanos (redes elétricas e telefonia), valores similares ao desse trabalho. A maioria desses problemas poderiam ser evitados com a presença de um planejamento eficiente a respeito da instalação da arborização urbana no município de Balsas- MA. A escolha correta das espécies a serem plantadas, agregadas a serviço de manejo de poda contribuem para minimizar todos esses problemas infraestrutura ocasionado por esses atos (Cabral, 2013).

\subsection{Concepção sobre a responsabilidade e consciência dos entrevistados}

Quanto as respostas referentes a responsabilidade e manutenção da arborização na cidade de Balsas-MA, 77\% dos entrevistados citaram que a prefeitura municipal deveria ser a única responsável pelo manejo da arborização e $23 \%$ que os moradores também devem se responsabilizarem. Dados próximos ao estudo realizado no distrito de Iara- CE, por De Almeida et al. (2019), 85\% responderam que prefeitura é a principal responsável pela arborização da cidade. Apesar do alto percentual nos dois trabalhos, a população também não se isentou de seus deveres quanto a manutenção e conservação do meio que vivem. De acordo com artigo 182, parágrafo 3 da constituição de 1988, o órgão municipal é o principal responsável pelo manejo da arborização urbana, devendo está anexada no plano diretor do município.

Tais competências devem ser explícitas nos planos diretores e nas leis do uso do solo, mesmo que, de acordo com as respostas sobre contribuição monetária, a maioria dos entrevistados disseram que contribuíram com 15 reais por ano para a melhoria da arborização (32,5 \% de respostas), o que mostra que apesar de indicar a Prefeitura como responsável, a população ainda assim percebe a relevância da arborização.

Entre as respostas, 18,6\% dos entrevistados responderam que não estariam dispostos a contribuir no manejo da arborização urbana na cidade, o que pode estar relacionado, de acordo (Rodrigues et al., 2010) a uma série de fatores, entre eles o nível socioeconômico da população entrevistada e desconfiança da destinação do recurso financeiro, além de descrença em relação a importância da arborização na melhoria da qualidade de vida. Diante disso, a criação de campanhas públicas por parte do poder público para enaltecer os benefícios da arborização é a principal ferramenta para mudar essa situação (De Oliveira et al., 2020).

É importante ressaltar que para os entrevistados o que deveria ser feito para a melhoria da urbanização a cidade seria plantar mais árvores $(37,7 \%)$, conscientização da população $(31,36 \%)$ e maior manutenção e podas de árvores $(27,35 \%)$, sendo este último relacionado para prevenir os efeitos negativos como crescimento de raízes de calçadas e contato com fiação elétrica.

\section{Considerações Finais}

De acordo com os resultados obtidos, a arborização na área central de Balsas caracteriza-se por apresentar a maioria dos seus indivíduos exóticos, destacando a espécie Azadirachta indica (Nim) 50,14\% e Mangifera indica (Mangueira) 5,15\% , o que torna-se perceptível a falta de diversidade entre as espécies, necessitando de estudo a longo prazo visando estabelecer medidas de implementação de novas espécies, preferencialmente nativas, que sejam viáveis para a cidade. Dentre as espécies nativas, o (Oiti) Licania Tomentosa apresentou maior percentual de 7,54\%; seguido do o (Ipê) Handroanthus sp 5,71\%. Em relação a percepção da população sobre a arborização da cidade, a maioria dos entrevistados possuem conhecimento das vantagens da arborização, apontando a melhoria da qualidade do ar e redução de calor como os principais benefícios. A maioria dos entrevistados citaram que a arborização não apresenta desvantagens; seguida dos problemas estruturais em calçadas; fiações elétricas e telefonia. 
Grande parte da população compreende a relevância que envolve a arborização e seus benefícios, além de reconhecer que a responsabilidade pela implantação é da prefeitura, contudo, cerca de 32,5\% dos entrevistados responderam que estariam dispostos a colaborar financeiramente para a manutenção da arborização urbana no município de Balsas. Considerando que conhecer o modo como a população pensa sobre o assunto pode auxiliar na elaboração de políticas de educação ambiental e, também, na futura gestão da arborização urbana do município.

Em trabalhos futuros, sugere-se a utilização de técnicas de geoprocessamento, determinar o Índice de Vegetação da Diferença Normalizada (IVDN) e com isso analisar áreas mais extensas, como por exemplo toda a área urbana da cidade, o que permitirá caracterizá-la por meio da distribuição e todo o processo de evolução da vegetação. Uma vez que esta técnica que poderá contribuir para qualidade dos dados sobre a vegetação da região sul maranhense.

Espera-se que o presente trabalho contribua com fornecimento de dados uma vez que o município de Balsas necessita da criação de política voltada a conservação de áreas já existentes, além da criação de novas áreas. Com isso, pode-se buscar melhorar as condições socioambientais para seus habitantes, por meio da elaboração de um Plano Municipal de Arborização Urbana que contemple ações permanentes de curto, médio e longo prazo.

\section{Referências}

Almeida, R., Scatena, L., \& Luz, M. S. D. (2017). Percepção ambiental e políticas públicas-dicotomia e desafios no desenvolvimento da cultura de sustentabilidade. Ambiente \& Sociedade, 20(1), 43-64.

Almeida, E. P., dos Santos Fernandes, S. P., \& Souto, P. C. (2019). Arborização urbana na percepção da população do distrito de Iara no Ceará. Revista da Sociedade Brasileira de Arborização Urbana.

Amato-Lourenço, L. F., Moreira, T. C. L., Arantes, B. L. D., Silva Filho, D. F. D., \& Mauad, T. (2016). Metrópoles, cobertura vegetal, áreas verdes e saúde. Estudos Avançados, 30(86), 113-130.

Araújo, H., Brito, S., Pinheiro, C., \& Medeiros Filho, S. (2017). A alelopatia aumenta o potencial invasor de Cryptostegia madagascariensis Bojer ex Decne.?. Enciclopédia Biosfera, 14(25).

Batista, F. A. (2012). Inventário quali-quantitativo da arborização urbana na cidade de Regímio - PB. Universidade Estadual da Paraíba. Campina Grande, Paraíba, Brasil.

Brianezi, D., Jacovine, L. A. G., Gonçalves, W., \& da Rocha, S. J. S. S. (2013). Avaliação da arborização no campus-sede da Universidade Federal de Viçosa. Revista da Sociedade Brasileira de Arborização Urbana, 8(4), 89-106.

Bobrowski, R., \& Biondi, D. (2012). Distribuição e dinâmica da área de copa na arborização de ruas de Curitiba, Paraná, Brasil, no período de 19842010. Revista Árvore, 36(4), 625-635.

Bonametti, J. H. (2020). Arborização urbana. Revista Terra \& Cultura: Cadernos de Ensino e Pesquisa, 19(36), 51-55.

Lei no 10.257, de 10 de julho de 2001. Regulamenta os arts. 182 e 183 da Constituição Federal, estabelece diretrizes gerais da política urbana e dá outras providências. http://www.planalto.gov.br/ccivil_03/leis/leis_20 01/110257.htm>.

Cabral, P. I. D., Perícia, A., \& Ambiental, G. (2013). Arborização urbana: problemas e benefícios. Revista Especialize On-line IPOG-Goiânia, 1(6).

Gerais, C. E. D. M. (2011). Manual de arborização. Belo Horizonte: Cemig/Fundação Biodiversitas.

Fabricante, J. R. (2014). Plantas Exóticas e Exóticas Invasoras da Caatinga-Vol. 1. Bookess.

Fabricante, J. R., Santos, J. P. B., de Araújo, K. C. T., \& Cotarelli, V. M. (2017). Utilização de espécies exóticas na arborização e a facilitação para o estabelecimento de casos de invasão biológica. Biotemas, 30(1), 55-63.

Firmo, D. H. T., Freitas, D. A., Durães, A. F. S., Silva, A. C., \& Almeida, E. F. A. (2019). Arborização urbana: uma imprescindível prática de manejo dos espaços urbanos. Brazilian Journal of Animal and Environmental Research, 2(5), 1584-1601.

Guerreiro, G. M., Gêa, B., \& Siqueira, M. V. B. M. (2020). Percepção ambiental da população sobre a arborização urbana na cidade barra bonita-SP. Revista da Sociedade Brasileira de Arborização Urbana, 15(1), 66-78.

Gonçalves, A., \& Meneguetti, K. S. (2015). Projeto de arborização como patrimônio da cidade. Ambiente Construído, 15(1), 99-118.

Günther, H. (2003). Como elaborar um questionário (Série: Planejamento de Pesquisa nas Ciências Sociais, n 01). Brasília, DF: UnB, Laboratório de Psicologia Ambiental, 36, 37-54. 
Hoppen, M. I., Divensi, H. F., Ribeiro, R. F., \& Caxambú, M. G. (2015). Espécies exóticas na arborização de vias públicas no município de Farol, PR, BRASIL. Revista da Sociedade Brasileira de Arborização Urbana, 9(3), 173-186.

IBGE, (2018). - Instituto Brasileiro de Geografia e estatística. https://cidades.ibge.gov.br/brasil/ma/balsas.

Kern, D. I., \& Schmitz, J. A. K. (2013). Arborização de vinte quarteirões amostrados na região central de Santa Cruz do Sul-RS. Revista da Sociedade Brasileira de Arborização Urbana, 8(3), 79-95.

Leão, T. C., Almeida, W. R., Dechoum, M. D. E. S., \& Ziller, S. R. (2011). Espécies exóticas invasoras no Nordeste do Brasil: contextualização, manejo e políticas públicas. Centro de Pesquisas Ambientais do Nordeste e Instituto Hórus de Desenvolvimento e Conservação Ambiental. Recife, PE, 99.

Lira Filho, J. D., Paiva, H. D., \& Gonçalves, W. (2001). Paisagismo: princípios básicos. Viçosa: Aprenda Fácil.

Silva, A. P. V. D., \& Lira, E. S. D. (2014). Diagnóstico da arborização urbana da área central de Corumbá/MS.

Lopo, D. (2014). Percepção, Diagnóstico e Gestão da Arborização e Áreas Verdes nas Cidades Fronteiriças Brasil - Bolívia. Dissertação de mestrado. Universidade Federal do Mato Grosso do Sul, MS, Brasil.

Meyer, A. (2015). Does education increase pro-environmental behavior? Evidence from Europe. Ecological economics, 116, 108-121.

Moro, M. F., \& Westerkamp, C. (2011). The alien street trees of Fortaleza (NE Brazil): Qualitative observations and the inventory of two districts. Ciência Florestal, 21(4), 789-798.

Pagliari, S. C., \& Dorigon, E. B. (2013). Arborização urbana: importância das espécies adequadas. Unoesc \& Ciência, 4(2), 139-148.

Periotto, F., Pituco, M. M., Helmann, A. C., dos Santos, T. O., \& Bortolotti, S. L. (2016). Análise da arborização urbana no município de Medianeira, Paraná. Revista da Sociedade Brasileira de Arborização Urbana, 11(2), 59-74.

Rabelo, L. K. L., de Castro Pires, E., Baumann, S. S. R. T., Santa Brígida, C. A., da Silva, J. B. S., da Silva Lima, P., ... \& de Aquino, M. G. C. (2019). Espécies frutíferas na arborização urbana do município de Santarém, Pará. Revista Ibero-Americana de Ciências Ambientais, 10(3), 335-341.

Rodrigues, T. D., Malafaia, G., Queiroz, S. É. E., \& de Lima Rodrigues, A. S. (2010). Percepção sobre arborização urbana de moradores em três áreas de Pires do Rio-Goiás. Revista de estudos ambientais, 12(2), 47-61.

Rufino, M. R., Silvino, A. S., \& Moro, M. F. (2019). Exóticas, exóticas, exóticas: reflexões sobre a monótona arborização de uma cidade brasileira. Rodriguésia, 70 .

Santos Alencar, L., Souto, P. C., de Alencar Moreira, F. T., Souto, J. S., \& Borges, C. H. A. (2014). Inventário quali-quantitativo da arborização urbana em São João do Rio do Peixe-PB. Agropecuária Científica no Semiárido, 10(2), 117-124.

Sampaio, A. B., \& Schmidt, I. B. (2013). Espécies exóticas invasoras em unidades de conservação federais do Brasil. Biodiversidade Brasileira-BioBrasil, (2), $32-49$.

Schvarstzhaupt, C. C., Reis, A.T. (2017). Vegetação urbana e instrumentos legais. Anais Enanpur (17)1.

Sjöman, H., Morgenroth, J., Sjöman, J. D., Sæbø, A., \& Kowarik, I. (2016). Diversification of the urban forest—can we afford to exclude exotic tree species? Urban Forestry \& Urban Greening, 18, 237-241.

Sousa, L. A., Cajaiba, R. L, Martins, J. S. C., Colácio, D. S., Sousa, E. S., Pereira, K. S. (2019). Levantamento quali-quantitativo da arborização urbana no município de Buriticupu-MA. Revista da Sociedade Brasileira de Arborização Urbana. 14 (1). 42-52.

Sufia, M. C. S., Souza, G. D. S., \& Siqueira, M. V. B. M. (2019). Percepção ambiental sobre arborização urbana em regiões distintas do município de BauruSP. Revista da Sociedade Brasileira de Arborização Urbana, 13(4), 15-28.

Valdiclei, C. J., Evaldo, O. F., Jeneffer, S. S. M., Diego, A.N., Marcelo, D. S., Josamar, G. S. J. (2017) Diagnóstico fitossanitário da arborização urbana no bairro Cidade Alta, Cuiabá Mato Grosso, Brasil. Revista Espacios, 38 (41). 25-34.

Ventura, D. (2002). Monografia jurídica. Porto Alegre: Livraria do Advogado. 